First Peoples Child \& Family Review

A Journal on Innovation and Best Practices in Aboriginal Child Welfare Administration,

Research, Policy \& Practice

\title{
Housing for Aboriginal Youth in the Inner City of Winnipeg
}

\section{Jason Brown, Dilly Knol, Sonia Prevost-Derbecker and Kelly Andrushko}

Volume 3, Number 2, 2007

Special Issue: Adolescent development, mental health, and promising research directions for Aboriginal youth

URI: https://id.erudit.org/iderudit/1069464ar

DOI: https://doi.org/10.7202/1069464ar

See table of contents

Publisher(s)

First Nations Child and Family Caring Society of Canada

ISSN

1708-489X (print)

2293-6610 (digital)

Explore this journal

Cite this article

Brown, J., Knol, D., Prevost-Derbecker, S. \& Andrushko, K. (2007). Housing for Aboriginal Youth in the Inner City of Winnipeg. First Peoples Child \& Family Review, 3(2), 56-64. https://doi.org/10.7202/1069464ar

\section{Article abstract}

Aboriginal families are highly overrepresented in child welfare caseloads. Major reasons for these high rates of involvement include poverty and housing issues, which contribute to perceptions of child neglect. In Winnipeg, the city with the highest proportion of Aboriginal peoples in Canada, low-cost housing is concentrated in core neighbourhoods. Homeless youth in these neighbourhoods, who are involved or have been involved in child welfare, were asked about their life experiences and the kind of housing that would help them. They talked about the need to be seen as resourceful, contributing members of the community, as well as their continued need of support from others, including friends and family. They wanted more than a place to sleep; they wanted a home that was safe, nurturing and long-term. The youth had school and work aspirations for themselves and wanted to help other youth reach their goals. There is a need for expansion of community-based and community-driven housing with youth who have been involved in the child welfare system.
Copyright ( Jason Brown, Dilly Knol, Sonia Prevost-Derbecker, Kelly Andrushko, 2007
This document is protected by copyright law. Use of the services of Érudit (including reproduction) is subject to its terms and conditions, which can be viewed online.

https://apropos.erudit.org/en/users/policy-on-use/ 


\title{
Housing for Aboriginal Youth in the Inner City of Winnipeg
}

\author{
Jason Brown ${ }^{a}$, Dilly Knol ${ }^{b}$, Sonia Prevost-Derbecker ${ }^{c}$, and Kelly Andrushko ${ }^{d}$
}

${ }^{a}$ Faculty of Education, University of Western Ontario, London, ON, Canada

${ }^{b}$ Andrews Street Family Centre, Winnipeg, MB, Canada

'Ndinawemaaganag Endaawaad Inc., Winnipeg, MB, Canada

${ }^{d}$ Red River College, Winnipeg, MB, Canada

\section{Introduction}

Aboriginal families remain highly overrepresented in Canadian child welfare caseloads. Indeed, "there are more children in the child welfare system and not with their families than there were children in residential schools at their height" (National Children's Alliance, 2005). While in operation between the late 1800 's and 1900's residential schools had devastating effects on Aboriginal families and communities; subsequent impacts of the schools have been felt by generations of survivors and their families. Assimilation was pursued through forced attendance of children aged 5-15, legislated by the Indian Act, requiring children to be turned over to the state for "education" (Blackstock \& Trocme, 2004). Many affected by the residential schools also had another negative experience of unwanted state intervention, as adults with their own children. Indeed, the 60's scoop, where many adoptions of Aboriginal children into non- $\mathrm{Ab}-$

Correspondence concerning this article may be addressed to:

J. Brown

Faculty of Education

University of Western Ontario

1137 Western Road, London,

Canada, N6G 1 G7

519-661-2111 ext. 88617 (voice), 519-661-2111 (fax)

Electronic mail may be sent to jbrow97@uwo.ca

\begin{abstract}
Aboriginal families are highly overrepresented in child welfare caseloads. Major reasons for these high rates of involvement include poverty and housing issues, which contribute to perceptions of child neglect. In Winnipeg, the city with the highest proportion of Aboriginal peoples in Canada, low-cost housing is concentrated in core neighbourhoods. Homeless youth in these neighbourhoods, who are involved or have been involved in child welfare, were asked about their life experiences and the kind of housing that would help them. They talked about the need to be seen as resourceful, contributing members of the community, as well as their continued need of support from others, including friends and family. They wanted more than a place to sleep; they wanted a home that was safe, nurturing and long-term. The youth had school and work aspirations for themselves and wanted to help other youth reach their goals. There is a need for expansion of community-based and community-driven housing with youth who have been involved in the child welfare system.
\end{abstract}

original homes took place, was yet another attempt by the state to assimilate Aboriginal children, by taking them through force from their families, communities, and cultures (Sinclair, 2007).

Generations of Aboriginal children who have been removed from their families by the state have not been exposed to role models that assist in the formation of healthy identities as Aboriginal peoples. Opportunities to learn about healthy parenting have also been taken away. "Child protection" for Aboriginal children has typically meant separation, trauma, and disconnection. The intergenerational impacts are multiple, and include problems with illness and relationships, as well as economic hardships, which contribute to the present-day over involvement of Aboriginal children in the child welfare system.

High rates of family poverty and inadequate housing among Aboriginal families have contributed 


\section{Authors Acknowledgements}

We are very grateful to the youth who took the time to share their stories and expertise with us. We would like to thank the community-based Boards of Directors at Andrews Street Family Centre and Ndinawemaaganag Endaawaad for their support of this study, and their willingness to partner with university researchers. We would also like to acknowledge the many contributions made by the wonderful staff at Andrews Street Family Centre and Ndinawemaaganag Endaawaad.

We are grateful to our funder, the National Secretariat on Homelessness, National Research Program on Homelessness.

We would also like to thank the research assistants on this project, including Lee Anne Jarman, Christine Miller, \& Darren Parenteau, for their great work.

to perceptions of child neglect and lead child welfare involvement (Trocme, Knoke, \& Blackstock, 2004). Contemporary responses, such as apprehensions and out-of-home placements, have been costly, financially, to the system, as well as socially and emotionally, to families and communities. However, apprehensions and out-of-home placements do not address the fundamental inequities that many Aboriginal families continue to experience. The effects of such ineffective child welfare responses are also passed from generation to generation. Youth who have had child welfare system involvement continue to experience the high rates of family poverty and housing challenges faced by their parents, and are left to struggle themselves with the same issues.

Numerous reports document the challenges faced by Aboriginal youth (MacKay, 2005; Turcotte \& Zhao, 2004; Fournier \& Crey, 1997; Mussell, Cardiff, \& White, 2004), homeless youth (Petrie \& McLean, 2005; Klodeawsky, Aubry, \& Farrell, 2006; Zamprelli, 2001), and some indicate that rates of child welfare involvement are high among these populations (Fitzgerald, 1995; Serge, Eberle, Goldberg, Sullivan, \& Dudding, 2002). However, there is much less available data on the experiences of Aboriginal youth who are homeless and have had child welfare involvement.

\section{Study Setting and Purpose}

In urban centers across the Canadian Prairie Provinces, low-income neighborhoods cluster in the inner cities, where Aboriginal populations are also high. In Winnipeg, housing and poverty issues are most visible in the inner city. Winnipeg has the highest proportion of Aboriginal peoples in Canada (Norris \& Jantzen, 2003). The population of Aboriginal peoples in Winnipeg cluster in the downtown core (Maxim \& Keane,
2003), where low-cost housing is highly concentrated (Distasio, Sylvester, Jaccubucci, Mulligan, \& Sargent, 2004). Despite high rates of family poverty and lack of adequate housing for residents, downtown core neighborhoods have a rich history of community involvement and strong social networks. Youth in these neighborhoods face multiple barriers, but also have many strengths and gifts to share. This study focuses on the issues, barriers and solutions to youth homelessness in Winnipeg's core neighborhoods from the perspectives of the youth themselves. Homeless youth who had been involved in child welfare, were asked about their life experiences and the kind of housing that would help youth in their community.

\section{Method}

Understanding the "problems" of groups facing multiple barriers has been of interest to researchers for some time. However, these groups have typically had few connections to researchers through which to influence the agenda (Greenwood \& Levin, 2000). As a result, participants have experienced little benefit from being researched because the results had no direct application to their realities. We wanted to design a research study that would yield results that could be directly applied toward improving the conditions for youth in the local community.

We used the principles of community-based participatory (CBPR) research to guide this project. CBPR is defined as "a collaborative approach to research that equitably involves, for example, community members, organizational representatives, and researchers in all aspects of the research process. The partners contribute unique strengths and shared responsibilities to enhance understanding of a given phenomenon and the social and cultural dynamics of the community, and integrate the knowledge gained 
with action to improve the health and well-being of community members" (Israel, Schulz, Parker, \& Becker, 1998, p. 175 ).

The research team included two agency directors, a university professor, two graduate students, and an undergraduate student, as well as a supervisory staff member within each of the community agencies, two youth who had been previous service recipients and six youth who were local residents. Members were called together to outline the purpose, identify research questions as well as sampling strategy for the study. Our purpose for the study was to identify the range of local issues associated with housing for homeless Aboriginal youth who had involvement with the child welfare system. The questions for this study were drafted by the six youth who were local community residents, and presented to the full research team. These questions are attached as an appendix. It was decided that local residents who were part of the research team would recruit participants through word-of-mouth.

Interviews were conducted in a variety of locations, based on each youth's preference. Locations included coffee shops, public parks, as well as meeting rooms within local agencies. Data were recorded using handwritten notes, since participants were not comfortable with audio-taping. The notes were typed out following the interview.

Data from the 30 interviews were shared with members of the research team in advance of a group meeting where they were to be discussed. The research team members discussed their own reactions to the interview transcripts. A potential data analysis procedure was proposed and discussed. Members agreed that a content analysis of the notes from interviews would be conducted in accordance with Creswell's (2003) procedure, including 1) arrangement of data into types, 2) reading through the data to get a general sense of the meaning, 3) initial coding of the information into chunks and labeling into categories, 4) detailed description about the people, places and events, and generation of codes for use with small number of categories, 5) discussion of each theme and, finally 6) interpretation of the data. This analysis task was undertaken by a graduate student member of the research team in consultation with a university professor. A draft of the results was circulated to members who provided feedback, which was incorporated into a final version. Team members approved the final ver- sion before it was made public.

\section{Results}

Twenty females and ten males, ages 13 to 21, who were involved in the child welfare system or had been involved in child welfare system, were asked about their experiences and solutions to homelessness. They were asked about their current living situation, their awareness and use of community resources, their present needs and future goals, and what would make a difference to homeless youth and families. The interview guide for these semi-structured interviews is attached in an appendix.

The majority of participants were born in Winnipeg, or in nearby communities. Some were born on Reserves from different regions of Manitoba. Those not born in Manitoba stated that they were born in other Canadian provinces. Three participants were from Nova Scotia, two were from British Columbia, and one was from Saskatchewan.

All of the youth lived in the North End at some point in their lives, or had a family or peer connection living in that area. Many stated that they presently had contact with at least one parent, but suggested that this contact was limited or nonexistent when they were homeless.

The duration of homelessness varied a great deal. Some stated that they had been homeless for only a few hours at a time, while others suggested longer lengths of time, stretching out from days, to weeks, to months. The shortest length of time homeless was a few hours, and the longest time was one year. However, some of the youth stated that they went through periods without a stable home. Several had a family history of homelessness.

When I was younger I was homeless along with my brother, sister and mom. I was homeless from the age 6 to around 11 years old. It was devastating to live without a home, we would stay in laundry rooms of apartment blocks, in the foyers of apartments and anywhere we could get warm especially in the winter.

My mom was living all over...she lived with her boyfriends but got into arguments so she left.

We also stayed at a shelter and with friends because my dad was very abusive to us. When I was 13 years old I left or got kicked 
out from my moms and lived on the street, I was never able to sleep properly and never felt safe.

The youth discussed using and/or relying on several community agencies, as well as adult and youth shelters. They also reported using the services offered by churches, food banks, soup kitchens, and drop-in programs.

Content analysis of interview data revealed six themes. Evidence of these themes appeared consistently across the interviews. These themes included: temporary living, sense of safety, being in control, support networks, future goals, and taking care of others.

\section{Temporary Living}

I'm in between places right now...got kicked out of a shelter, and don't have an apartment yet...went to check out the one they (welfare) wants me to move into, but it is full of rat shit, and there's no lock on the door, the windows are broken, light switches don't work and it smells...

Youth described their experiences of multiple short-term living situations.

Ijust went from home to home, from the time I was 16 years old till about 17 and half. I just wandered around. My mom tried to find me but couldn't.

... been bouncing around for five years, between placements and friends.

... we have nowhere to live, staying at a friends place...basically back and forth like.

To many youth, homelessness meant not having shelter. It also meant being vulnerable to the elements and lacking basic necessities.

People that are living on the street, sleeping on benches and in front of stores...that's homelessness.

People having to sleep under bridges, no shelter.

Homelessness is how people have to eat out of garbage cans... have to live in a bus shelter, have to ask for spare change...

When asked about their present living conditions, the youth talked about how they had shelter, but that it was a limited term arrangement.
I am staying at my sisters until Sept.01 until I get my own place. She lives in the North End.

Right now I am homeless. I am staying with my sister in the North End...it's been about one month. It's good in a way but stressful because you don't have your own place.

Some described the quality of their present living conditions as poor, and that they would gladly move if they could.

I have my own place now...it is really bad though... when it rains, it comes inside... it is in the central area, but the landlord is bad... I've been staying at my sister's because my place smells so bad and is falling apart...I called a health inspector and they are kicking everyone out of the place, so I have to find a new place to live in two weeks...

I am on a waiting list for public housing. It would make a difference because it's a house and its decent looking compared to now.

\section{Sense of Safety}

The youth described how they felt about personal safety in their own relationships, both while they were homeless and in their present living situations.

I lived with my boyfriend for a while, but he was very abusive...I stayed with friends for a while, and some other family, but that wasn't so great....

My boyfriend was out of control at times and used to break windows and bang on my door making too much noise, so I would get evicted.

The power held over them by the private landlords in control of their accommodations also threatened their safety.

Well, the landlords come and harass us for money for rent... money we don't have...they don't understand that welfare pays for our housing.

Youth also talked about their concerns about personal safety within the neighbourhood they lived in.

...was homeless before...was almost stabbed in the face but blocked with my forearm....

Gangs make it difficult. I was stabbed.

When you are walking around getting jumped out of nowhere...you could get 


\section{Housing for Homeless Aboriginal youth in the Inner City of Winnipeg}

jumped for wrong colors...they could stab you, you could get shot.

The drinking was pretty bad in the area and I worried about the kids around there...I liked having my own place, privacy, my space but the drinking and fighting around there wasn't good.

However, their feelings of safety were also improved, in some ways, because of their social connections and familiarity with resources in the neighborhood.

Everybody (neighbors) know each other, if there is something suspicious happening in the neighborhood they notify someone. Everybody is always looking out for each other.

The neighbors are friendly. They help me out with my kids.

... most people are really nice here, and there are lots of resources around...

I live at a safe house now... I know I have a place to go that is safe and I don't have to worry...most of my friends live with their parents...not scared about anything, myself, in this neighborhood... if you look scared you might be a target, but if you look confident people won't want to fight you...

\section{Being in Control}

The youth talked about feeling a lack of control over their lives. They coped with this by taking control of their circumstances in different ways while homeless. Some felt scared and lonely. They worried about finding something to eat, and not knowing what was going to happen next.

I was forced to leave my families house; took everything I could pack.

I was sexually abused by my dad so I don't bother with him anymore. My mom doesn't know about it, so I only see or talk to her every once in awhile.

I got locked out of my mom's place, my aunty didn't want me, and my sister didn't care...I was so scared, Ijust walked around all night... that was the only time I was homeless...

When I was homeless I felt so unwanted and I wanted to commit suicide at that time.

...it gets lonely when you're homeless...it hurts that your family can't look after you anymore because they've got their own

things going on...

Not all of the youth felt accepted into the homes of friends or family. For them, there was a price tag for this help, and some felt they were being taken advantage of.

I didn't like staying with other people because I had to look after all the kids...mine, plus 4 others or more, and they take off and leave you with them...you can't complain because you're staying there, but you also feel taken for granted...

The youth talked about their desire for independence, the benefits as well as responsibilities that came with it, as well as how they made ends meet.

Since I was 16, I've lived on my own...it is good in that you have your own rules to live by and no one telling you what to do.

It was great living on my own because you can do whatever you want... you just have to worry about your bills and food.

Panhandled, stole, shoplifted and sell what I stole, also my boyfriend would jump people and take their money for us.

In terms of money being a problem, it depends on the circumstances. I can get money but its how I get the money. I scam, hustle, and steal...I do whatever I need to do.

The future they wanted involved employment and education. However, the changes needed to reach their goals had to be on their own terms.

Hopefully I'll be working and living on my own this time, next year.

Lots of people could help, but I need to want to help myself.

...you've gotta help yourself...they (agency staff) sure helped me figure out that I needed to make things happen for myself and that no-one was going to do it for me...

\section{Support Networks}

The youth described the nature of their support network. They talked about the positive impact of getting emotional support from family members.

...my ex's mom was like a sister to me...she was 31 and could relate because she'd been there, too...

I have sisters in this neighborhood and we 
all encourage each other...

My grandparents are around to help me out.

While they all needed help at one point or another, the family supports available changed frequently.

...my boyfriend knows people, has friends and family here...we're staying with his sister right now, and that's going good...

...my mom and sister help me out with food and money... more my sister...

...my uncle helps out...he's got a place on the reserve, but comes into Winnipeg when he gets welfare to help us out with groceries...we share, and look after each other...

The youth talked about the support provided by agencies in the community, as well as professionals who made a difference in their lives and the lives of their children.

the agencies helped me out...they had a bed for me, and they got me to reopen my CFS file...

...there is one place that helps me out a great deal. My son likes it there, too. He goes there early in the morning until 8:30pm. They have a program for young mothers...they take out mom's and baby-sit kids.

...probably the people who helped me the most were some teachers and a probation officer...

They appreciated being close to where their friends, and families lived, as well as the services that were nearby.

I like the neighborhood...it's a nice neighborhood. My sister is near here and there are enough friends around to rely on.

Living in this neighborhood, I'm close to all resources and family.

My sister lives about 5 houses away and my mom and brother live about 4 blocks away...counseling services are close by and the counselors even come to my house. I'm in a program now... live there, and take classes...they help me a lot with my issues...I knew about the program for a while, but didn't think I needed to be there...my first son's granny worked there, and told me about it...

\section{Future Goals}

(C) Jason Brown, Dilly Knol, Sonia Prevost-Derbecker, and Kelly Andrushko
No matter what their current situations were, the youth had concrete goals in mind for their futures. These goals included centered around education, employment, and longer-term living arrangements.

Next year I want to be graduating high school, then living on my own. I need to stay in school and choose the right friends.

Having my own place, getting a job, having money, putting resumes out there to find a job.

I hope I'll be working, like to go back to school in September, to college to upgrade my high school courses.

I want to finish my high school...have one more year to go, and then done...w want to go to college or university after and become a counselor or therapist...

...next year, I'd like to be finished high school and be able to go into child care or youth work...but, I want to take a year off and work, too...

The youth also talked about the services that they needed to help them achieve their goals.

I'd like to better my self as a parent.

Going to programs (drug, parenting) would help me. Also go to an Adult Education program for my grade 12 would help as long as they had a daycare right in the school.

I'd like to go back to university. I was taking Law so I'd like to keep doing that. I would need to get my kids in daycare first though...I would need to get sponsored by my band again so I can have money to live on. I have friends who will help me out and I have myself. I am brave enough to go back to school and that's a start.

\section{Taking Care of Others}

The youth discussed what they thought would be useful to help others in similar situations. For immediate help, they noted that more shelters, drop-in programs, safe houses, and community centres were needed. Recommendations were also made to expand existing agencies.

A huge house where anyone could stay...I'd like to buy out all of the staff here, and open my own house, where I made the rules... have TV's and air conditioning in each room...

More places like around here, get kids 


\section{Housing for Homeless Aboriginal youth in the Inner City of Winnipeg}

off the streets, places need to be open longer hours and all night.

...someplace where the youth can also go to school, and go on outings...

...need activities for moms and kids separate and together...it would be ideas to have an apartment for kids, like a bachelor apartment, with its own cooking and bathroom stuff...but with adults there, so that you could have someone older to talk to, when you needed it... we also need programs for the young ones because they run away for so many different reasons...they are in desperate need to stop the drugs, but people get in too deep...

...I would like to volunteer and mentor to kids who need someone older to talk to...but you need to make sure that the mentor has been there and done that and has outgrown it, be clean and straight...

Addiction support is needed and education is a big help. The youth need 24-hour programs that they can go to for support

For longer-term assistance, help reconnecting with family and the community, as well as schools was needed. Several mentioned that housing, education, and employment skills training would be helpful.

Employment would help would help youth also reconnecting with family and addiction services could help the youth.

Education is important, kids need a place where they won't be judged, where someone won't call the police or their parents on them. They need counseling but so many teenagers are scared of adults and so many adults are afraid of teenagers...Awareness groups would help people become aware of homeless youth, maybe have people speak to junior highs about homelessness issues... people need to be more understanding of teenagers.

Get these kids to go to school, teach them to help themselves, work experience, to find them a clean home and shower...Put them in drop in centers, so they can feel safe, no worries about violence. Get youth involved in sports, it keeps the violence away.

Housing and employment to get kids off the street and more drop-in centres would help the kids. 24 hours places would help; something for them to do like being able to play basketball at 2 in the morning would also help.

The youth also discussed the need for information. This included counseling services, access to Internet, and access to information about services.

There are lots of places youth can go for food, and shelter... there's lots out there, people just don't go to these places...maybe they don't know about them...

Didn't turn to anyone, didn't know what was out there, felt like the bad kid.

More publicity is needed on youth homelessness and the services they can contact.

I didn't know anything about any resources, so maybe they should do more advertising about where to go if you're homeless. There should be somewhere that you can call at anytime, and a 24-hour drop in centre with counseling, with a place to sleep for shelter.

Older people who have been homeless talking to homeless youth...if they have been through the same situation they could discuss it.

\section{Discussion}

Homeless Aboriginal youth in the inner city are not a homogeneous population. Their experiences and situations are as unique and varied as their future goals and directions. However, the frequency of child welfare involvement among youth who are homeless is a serious concern. The realities of their early family experiences, including poverty and inadequate housing, are also concerning. Interestingly, the youth we spoke to did not dwell on the past, but remained oriented to the present and the future. They spoke about their struggles, but not to complain. Rather, they spoke about their struggles as a way to share their collective abilities to sustain themselves and care for others, despite considerable adversity.

Their realities included multiple moves over short periods of time, from varied arrangements with different family members and friends. They did what they could to keep themselves safe throughout these many transitions, by knowing where they were and deciding who they could trust. They left when they felt unsafe. They did what they had to do to get by with the few income opportunities they had to work with. They wanted security and support, but not at a personal cost that would compromise their inde- 
pendence. They wanted to find the right balance for themselves.

The problems the youth had with private market and public housing reflected the same challenges their parents and other families faced. They had difficulty finding decent, local, affordable housing. Multiple challenges such as absentee landlords, dirty conditions, shady deals for rent, and unsafe buildings, were reported. However, these were the only places that they could afford. For many youth, the local community did offer support in terms of people and organizations they had good relationships with. The challenge was finding a decent place to live, with the right amount of stability and support. The youth also wanted educational upgrading or training and work experience that lead to a living wage job, close by.

The challenges faced by local youth who have been involved in child welfare affect only the youth, but their families and the greater community. However, the lack of local housing, educational and employment opportunities for youth when they turn 18, create huge barriers obtaining the personal, educational and work skills they need to achieve the level of independence they want. The youth themselves have identified the need for housing models that help them find the right balance of skills and experience, in a setting where they receive the social support they need, within the community where their friends and family live, in a city where they are seen as assets for the future.

Local community-based agencies are providing much-needed and effective services to Aboriginal youth in the inner city. These organizations, based local leadership and the strengths of residents, are well placed to deliver the needed services within the community. What is needed is the commitment of government resources to the expansion into more housing for youth.

\section{Conclusion}

Homeless youth who were involved in the child welfare system have many strengths, including self-control, resourcefulness, friendship, sharing, protecting, looking to the future, and as well as a desire to take care of others. The youth are actively involved, and interested in continuing to be involved in the development of local resources for their friends and families in their local community.

The solutions, from the perspective of youth themselves, lie in valuing their contributions, allowing them to grow as individuals and parents by providing gentle guidance from well-intentioned others within their community. Punitive responses have not, and will not work. The need for a safe place to live, where there is the right amount of support nearby, and resources for re-entry into school or a job.

A significant gap is the absence of supportive housing for youth after they reach the age of 18 . Inner city communities have the expertise, but a greater commitment of government resources to address root causes of homelessness among youth their families, namely less poverty and more affordable housing, are needed. The funding and development of second stage housing models, based on local community-identified priorities, are needed to ensure that youth leaving the child welfare system do not become homeless.

\section{Bios}

Jason Brown is an Assistant Professor in the Faculty of Education at the University of Western Ontario, London.

Dilly Knol is Executive Director of Andrews Street Family Centre, Winnipeg, Manitoba. Andrews Street Family Centre is a family resource center that builds on its community strengths and encourages its individuals, children, elders, families, and youth to reach their full potential, through support, friendship, and positive experiences.

Sonia Prevost-Derbecker is Executive Director of Ndinawemaaganag Endaawaad Inc., Winnipeg, Manitoba. Ndinawemaaganag Endagwaad Inc. is a non-profit organization that has been operating since 1993 in conjunction with other service agencies in the North End of the city. Ndinawe currently operates a short-term residential safe house for street children aged 11 to 17 who are in need of a safe place to stay, as well as an outreach centre for youth.

Kelly Andrushko is an Instructor in the Early Childhood Education Program at Red River College, Winnipeg, Manitoba.

\section{References}

Blackstock, C., \& Trocme, N. (2004). Community based child welfare for Aboriginal children: Supporting resilience through structural change. Retrieved April 10, 2007 from: http://www.cecw-cepb.ca/files/file/en/ communityBasedCWAboriginalChildren.pdf

Centre for Excellence for Child Welfare (2006). Prairie fo- 
rum policy summary. Retrieved August 21, 2006 from: http://www.cecw-cepb.ca/DocsEng/PrairieForumPolicySummary.pdf

Distasio, J., Sylvester, G., Jaccubucci, C., Mulligan, S., \& Sargent, K. (2004). First Nations/Metis/Inuit mobility study. Winnipeg: Institute of Urban Studies.

Fitzgeraald, M. (1995). Homeless youths and the child welfare system: Implications for policy and service. Child Welfare, 74, 717-729.

Fournier, S., \& Crey, E. (1997). Stolen from our embrace: The abduction of First Nations children and the restoration of Aboriginal communities. Vancouver, BC: Douglas \& McIntyre.

Klodawsky, F., Aubry, T., \& Farrell, S. (2006). Care and lives of homeless youth in neoliberal times in Canada. Gender, Place and Culture, 13, 419-436.

MacKay, G. (2005). The city as home: The sense of belonging among Aboriginal youth in Saskatoon. Saskatoon, SK: Bridges and Foundations.

Maxim, P., Keane, C., \& White, J. (2003). Urban residential patterns of Aboriginal people in Canada. In Not strangers in these parts: Urban Aboriginal Peoples, edited by D. Newhouse and E. Peters, Ottawa: Policy Research Initiative. 